\title{
Treatment Pattern and Overall Survival of Patients with Advanced Non-Squamous Non-Small Cell Lung Cancer: A Multicentric Real-World Study in China (CTONG1506)
}

Qing Zhou

Guangdong Provincial People's Hospital \& Guangdong Academy of Medical Sciences

Yong Song

Nanjing General Hospital of Nanjing Military Command

Xin Zhang

Zhongshan Hospital, Fudan University

Gongyan Chen

Harbin Medical University Cancer Hospital

Yiping Zhang

Zhejiang Cancer Hospital

Ping Yu

Sichuan Cancer Hospital

Jianhua Chen

Hunan Cancer Hospital

Zhuang Yu

The Affiliated Hospital of Qingdao University

Yi Hu

Chinese People's Liberation Army General Hospital

\section{Xia Song}

Shanxi Cancer Hospital

Diansheng Zhong

Tianjin Medical University General Hospital

Guosheng Feng

People's Hospital of Guangxi Zhuang Autonomous Region

\section{Lulu Yang}

Lilly Suzhou Pharmaceutical Co.,Ltd

\section{Lu jing Zhan}

Lilly Suzhou Pharmaceutical Co., Ltd

\section{Xiao Ma}

Lilly Suzhou Pharmaceutical Co.,Ltd 


\section{Xingwei Lu}

Shanghai Centennial Scientific Co.,Ltd

\section{Yi-Long Wu (D syylwu@live.cn )}

Guangdong Lung Cancer Institute

\section{Research article}

Keywords: non-squamous non-small cell lung cancer, tyrosine kinase inhibitors, chemotherapy, overall survival, treatment patterns

Posted Date: June 2nd, 2020

DOI: https://doi.org/10.21203/rs.3.rs-29336/v1

License: (c) (i) This work is licensed under a Creative Commons Attribution 4.0 International License.

Read Full License 


\section{Abstract}

Background:

CTONG1506, an observational study assessed the real-world treatment patterns and overall survival (OS) of Chinese advanced non-squamous non-small cell lung cancer (NSCLC) patients in current treatment practices.

\section{Methods:}

Patients initiated with 1 st line therapy were identified from 12 tertiary hospitals across China. Survival data were collected 1- and 2-years after study initiation. OS was estimated using the Kaplan-Meier method.

\section{Results:}

Among 540 patients with survival data, median OS was 21.4 months ( $95 \% \mathrm{Cl}: 18.1-25.5)$, and 2-year OS rate was $46.3 \%$ (95\% Cl: 42.0\%-51.0\%). Median OS for patients with epidermal growth factor receptor $(E G F R+)$ mutation $(\mathrm{n}=203)$, anaplastic lymphoma kinase $(A L K+)$ rearrangement $(\mathrm{n}=24), E G F R-/ A L K$ were 27.9 months (95\% Cl: 23.4-NA), 24.5 months (95\% Cl: 18.1-NA), and 15.7 (95\% Cl: 13.1-21.1) months, respectively. Median OS was not reached in EGFR exon 19 deletion patients compared to EGFR exon 21 L858R mutation patients (21.4 months, 95\% Cl: $16.7-35.6, \mathrm{P}=0.038) .93$ EGFR + patients received tyrosine kinase inhibitor $(\mathrm{TKI})$ alone, 21 received chemotherapy alone and 66 received TKI and chemotherapy [median OS 25.5 months, 18.1 months, and 35.6 months, respectively]. For EGFR + patients, TKI alone was the preferred therapy in $1 \mathrm{st}(58.2 \%)$ and $2 \mathrm{nd}(56.8 \%)$ line when compared to chemotherapy (35.1\% and $31.1 \%$ respectively). In 3rd line, chemotherapy was preferred (46.0\%) over TKI only $(38.0 \%)$ in these patients.

\section{Conclusions}

OS for patients with advanced non-squamous NSCLC patients aligned with previous trials. EGFR+ patients who received both TKI and chemotherapy had longer median OS, which is consistent with results from other trials.

\section{Background}

Lung cancer is the leading cause of mortality with incidence of 2.1 million new cases and 1.8 million deaths in 2018 world-wide (1). In China, lung cancer remains the most common issue, accounting for $18.1 \%$ of new cases and is also the leading cause of cancer death (2). It has been reported that the 5 -year survival of patients diagnosed with lung cancer is around $17.8 \%$ and patients die within one year of diagnosis (3). The 5- year survival rate for lung cancer in China remains low in men with frequency of $16.8 \%$ and $25.1 \%$ in women from 2012-2015 (4). Additionally, an increase in the incidence and mortality with age in both the genders is observed (5). 
The international treatment guidelines recommend chemotherapy, programmed death ligand 1 (PDL-1), or combination of PDL1 and chemotherapy, as first line treatment for NSCLC without oncogenic driver mutations (6). In patients with epidermal growth factor receptor (EGFR) mutations and anaplastic lymphoma kinase $(A L K)$ rearrangements, tyrosine kinase inhibitors (TKIs) are the recommended first-line treatment.

Approximately, $19.2 \%$ of Western and $47.9 \%$ of Asian population with NSCLC- adenocarcinoma subtype harbour EGFR mutation (7). Thus, TKIs directed against EGFR, such as Erlotinib, and Gefitinib, have demonstrated promising outcomes for this subgroup of patients (8); thereby representing as a standard first-line treatment for EGFR mutated NSCLC (9).

Additionally, superiority of EGFRTKIs over platinum-doublet chemotherapy in providing better progression free survival (PFS) in EGFR+ NSCLC has also been demonstrated by various randomized, phase III studies (10-16). Similar findings have also been reported in other studies wherein prolonged PFS relative to chemotherapy was observed with Afatinib but overall survival (OS) was similar in both groups (17). Evidence suggests that treatment with EGFR TKI in first line setting improves PFS but did not show much benefit in OS compared to chemotherapy (10-12).

Despite growing evidence in proving the efficacy of various therapeutic strategies, limited information concerning the use of appropriate treatment modality for advanced NSCLC in a real-world setting raises a serious concern to the clinicians. Therefore, data from real-world will help generate evidence on the effectiveness and use of medical products in daily practice (18), will provide insights on patient response, disease patterns, along with clinical outcomes in patients of all ages (19). This study was thus conducted to assess the treatment patterns and OS of advanced non-squamous NSCLC patients in a Chinese population in current treatment practices (CTONG 1506).

\section{Methods}

\section{Study design}

This retrospective, series of cross-sectional study extracted data from medical charts of patients discharged from 12 tertiary hospitals across China between August 2015 and March 2016. The protocol was approved by the Research Ethics Committee of the Guangdong General Hospital, Guangzhou, Guangdong, China.

The study was conducted in accordance with the Declaration of Helsinki and Good Clinical Practice and was supported by the Chinese Thoracic Oncology Group (CTONG study number 1506).

\section{Study population}

The medical charts of patients meeting the following criteria were included for review: aged $\geq 18$ years; diagnosis of unresectable Stage IIIB or IV (according to the American Joint Committee on Cancer staging system, 7th edition), non-squamous NSCLC; no previous systemic anticancer treatment for Stage IIIB or IV 
disease; and most recent hospitalization was for anticancer treatment. Patients aged $<18$ and $>80$ or diagnosed with squamous cell carcinoma or stage $\mathrm{l} / \mathrm{II}$ or not imitated on treatment and non-hospitalised patients were excluded from the study. A total of 540 patients with 2-year survival data were identified in this survey and included in analysis.

\section{Data collection}

Data from patients' medical charts were extracted and entered into the Medical Record Abstraction Form (MERAF) by designated hospital staff after patient discharge. Extracted data included demographics, NSCLC histological type, Eastern Cooperative Oncology Group (ECOG) performance status (PS), gene aberration status and first-line anticancer treatment regimen. Data entry was reviewed on-site by an independent data management organization (Shanghai Centennial Scientific Ltd., Shanghai, China), who assessed accuracy of data entry by checking $20 \%$ of all MERAFs collected at one hospital selected at random. Completed MERAFs were collected for analysis. Data from all collected MERAFs were entered into a database for analysis, with data entered and verified twice to ensure accurate data entry. MERAFs were excluded from analysis if data were missing for gene aberration test status or first-line anticancer treatment regimen and if more than $10 \%$ of other data were missing.

\section{Study outcome}

Survival information OS was collected one and two years after patients received initial treatment. Followup data was obtained from medical chart abstraction or telephonic interview.

\section{Statistical analysis}

Age $(<65, \geq 65)$, sex (male, female), hospital location (hospital location, developed area), smoking status (never smoker, former smoker, current smoker), histological subtype (adenocarcinoma, other), ECOG PS $(0,1, \geq 2)$ at baseline were described. The categorical data were presented as frequencies and percentages. OS were evaluated by Kaplan-Meier (KM) method with $95 \%$ confidence intervals (Cls). Patients who lost the follow-up or could not be confirmed about survival status at any follow-up were not included in the survival analysis. Two-tailed P-values, less than 0.05 will be considered statistically significant. All analysis was performed using R software (Version 3.5.1).

\section{Results}

\section{Baseline and demographic details}

The demographic and baseline clinical characteristics of the overall study population was categorized based on mutational status as presented in Table 1. Among the 12 tertiary hospitals that were included in the study, majority of hospitals belonged to developed area in China. A total of 540 patients who had a 2year follow-up survival data were included in the study. There were 183 patients with EGFR-/ALK-wild type and most of them were $<65$ years of age $(72.1 \%)$. It was seen that $74.6 \%$ of the included patients 
were $<65$ years. A total of 87 (42.8\%) patients had exon 19 deletion and $82(40.3 \%)$ patients had EGFR exon 21 L858R mutation in EGFR+ group.

Table 1

Demographic and baseline characteristics of patients

\begin{tabular}{|c|c|c|c|c|}
\hline Characteristic, n (\%) & $\begin{array}{l}\text { Total } \\
n=540\end{array}$ & $\begin{array}{l}E G F R+ \\
\mathrm{n}=203\end{array}$ & $\begin{array}{l}A L K+ \\
\mathrm{n}=24\end{array}$ & $\begin{array}{l}\text { EGFR-\&ALK- } \\
\mathrm{n}=183\end{array}$ \\
\hline \multicolumn{5}{|l|}{ Age } \\
\hline$<65$ years & $403(74.6)$ & $142(70.0)$ & $20(83.3)$ & $132(72.1)$ \\
\hline$\geq 65$ years & $137(25.4)$ & $61(30.0)$ & $4(16.7)$ & $51(27.9)$ \\
\hline \multicolumn{5}{|l|}{ Sex } \\
\hline Male & $310(57.4)$ & $86(42.4)$ & $14(58.3)$ & $132(72.1)$ \\
\hline Female & $230(42.6)$ & $117(57.6)$ & $10(41.7)$ & $51(27.9)$ \\
\hline \multicolumn{5}{|l|}{ Hospital location } \\
\hline Developing area & $197(36.5)$ & $68(33.5)$ & $7(29.2)$ & $53(29.0)$ \\
\hline Developed area & $343(63.5)$ & $135(66.5)$ & $17(70.8)$ & $130(71.0)$ \\
\hline \multicolumn{5}{|l|}{ Smoking status } \\
\hline Never smoker & 306 (56.9) & $142(70.3)$ & $16(66.7)$ & $78(42.6)$ \\
\hline Former smoker & $129(24.0)$ & $34(16.8)$ & $3(12.5)$ & $56(30.6)$ \\
\hline Current smoker & $103(19.1)$ & $26(12.9)$ & $5(20.8)$ & $49(26.8)$ \\
\hline \multicolumn{5}{|l|}{ Histologic subtype } \\
\hline Adenocarcinoma & 516 (95.9) & 201 (99.5) & $24(100.0)$ & $170(92.9)$ \\
\hline Other & $22(4.1)$ & $1(0.5)$ & $0(0.0)$ & $13(7.1)$ \\
\hline \multicolumn{5}{|l|}{ ECOG PS } \\
\hline 0 & $173(32.2)$ & 63 (31.2) & $5(20.8)$ & $53(29.0)$ \\
\hline 1 & $316(58.7)$ & $122(60.4)$ & $18(75.0)$ & $110(60.1)$ \\
\hline$\geq 2$ & $49(9.1)$ & $17(8.4)$ & $1(4.2)$ & $20(10.9)$ \\
\hline
\end{tabular}

ALK: Anaplastic Lymphoma Kinase; ECOG PS: Eastern Cooperative Oncology Group Performance Status; EGFR: Epidermal Growth Factor Receptor

Treatment pattern in various lines of therapy 
It was seen that in EGFR+ patients, TKI only was the preferred mode of therapy in 1st (58.2\%) and 2nd (56.8\%) line when compared to chemotherapy (35.1\% and 31.1\% respectively). In 3rd line, chemotherapy was preferred (46.0\%) over TKI only (38.0\%) in these patients.

On the other hand, chemotherapy only was the most common mode of treatment in $A L K+$ patients in $1 \mathrm{st}$ (58.5\%) and 2nd (59.1\%) line. However, chemotherapy and TKI was prescribed as 1 st line to $2.0 \%$ EGFR+ and $4.6 \% A L K+$ patients in 2 nd line. None of the patients received this pattern at 3rd line (Table 2).

Table 2

Treatment patterns across the lines of therapy

\begin{tabular}{|lllll|}
\hline Line of therapy & EGFR+ & Wild-type & ALK+ & Wild-type \\
\hline Ist line & & & & \\
\hline TKI only $(\mathrm{n}=146, \%)$ & $58.2 \%$ & $8.4 \%$ & $39.0 \%$ & $32.0 \%$ \\
\hline Chemotherapy only $(\mathrm{n}=88, \%)$ & $35.1 \%$ & $83.1 \%$ & $58.5 \%$ & $59.6 \%$ \\
\hline Chemotherapy plus TKI $(\mathrm{n}=5, \%)$ & $2.0 \%$ & $1.2 \%$ & $0.0 \%$ & $1.3 \%$ \\
\hline 2nd line & & & & \\
\hline TKI only $(\mathrm{n}=75, \%)$ & $56.8 \%$ & $15.0 \%$ & $31.8 \%$ & $36.5 \%$ \\
\hline Chemotherapy only $(\mathrm{n}=41, \%)$ & $31.1 \%$ & $64.0 \%$ & $59.1 \%$ & $47.6 \%$ \\
\hline Chemotherapy plus TKI $(\mathrm{n}=1, \%)$ & $0.8 \%$ & $2.0 \%$ & $4.6 \%$ & $1.6 \%$ \\
\hline 3rd line & & & & \\
\hline TKI only $(\mathrm{n}=19, \%)$ & $38.0 \%$ & $21.1 \%$ & $62.5 \%$ & $28.1 \%$ \\
\hline Chemotherapy only $(\mathrm{n}=23, \%)$ & $46.0 \%$ & $44.7 \%$ & $12.5 \%$ & $42.1 \%$ \\
\hline Chemotherapy plus TKI $(\mathrm{n}=0, \%)$ & $0.0 \%$ & $0.0 \%$ & $0.0 \%$ & $0.0 \%$ \\
\hline
\end{tabular}

ALK: Anaplastic Lymphoma Kinase; EGFR: Epidermal Growth Factor Receptor; TKI: Tyrosine Kinase Inhibitor

\section{OS in patients with different mutations}

The median OS for 540 patients was 21.4 months (95\% Cl: 18.1-25.5), 1-year and the 2-year OS rate was $69.5 \%$ (95\% Cl: $66.0-74.0)$ and $46.3 \%$ (95\% Cl: $42.0-51.0)$, respectively (Fig. 1A). It was seen that the median OS for patients with EGFR mutation $(\mathrm{n}=203), A L K$ rearrangement $(\mathrm{n}=24)$, and wild-type $E G F R$ with negative $A L K$ rearrangement $(\mathrm{n}=183)$ were 27.9 months (95\% Cl: $23.4-\mathrm{NA}), 24.5$ months $(95 \% \mathrm{Cl}$ : 18.1-NA), and 15.7 months (95\% Cl: 13.1-21.1), respectively (Fig. 1B).

Median OS was not reached in patients with EGFR exon 19 deletion and it was 21.4 months $(95 \% \mathrm{Cl}$ : 16.7-35.6) in EGFR exon $21 \mathrm{~L} 858 \mathrm{R}$ mutation patients. Statistically significant difference $(\mathrm{P}=0.038)$ was seen in OS between the groups (Fig. 2). 


\section{OS in patients with various 1 st line treatments}

In EGFR+ patients, the median OS was 27.9 months (95\% Cl: 19.3-35.6) in patients receiving TKI in the first-line setting; whereas in EGFR+ patients who received chemotherapy, the median OS was 27.7 months (95\% Cl: 19.5-NA) with log rank $\mathrm{P}=0.36$ (Fig. $3 \mathrm{~A})$. Even in $A L K+$ patients, TKI was the most common first-line treatment regimen $(62.5 \%, 15 / 24)$, while the median OS was not reached.

In patients with EGFR-/ALK- 84.2\% (154/183) received first-line chemotherapy, with a median OS of 14.5 months (95\% Cl: $12.6-19.4)$. It was seen that median OS in patients treated with pemetrexed-based and non-pemetrexed-based chemotherapy were 15.6 months (95\% Cl: 13.1-21.1) and 12.6 (95\% Cl: 10.6-33.9) months, respectively with log rank $\mathrm{P}=0.65$ (Fig. 3B).

\section{OS in EGFR + patients in all treatment course}

TKI was administered to 93 EGFR + patients, whereas 21 received chemotherapy alone, and 66 received both TKI and chemotherapy sequentially. The median OS of these three group of patients was 25.5 months (95\% Cl: 19.3-NA), 18.1 months (95\% Cl: 12.1-NA), and 35.6 months (95\% Cl: 24.4-NA), respectively with log rank test: $\mathrm{P}=0.25$ (Fig. 4).

\section{Discussion}

This study evaluated the real-world treatment patterns and the survival benefits provided by EGFR TKIs and other current, systemic anti-cancer therapies in advanced NSCLC with different mutated and nonmutated profiles in China. The treatment pattern observed in current study is in agreement with the Chinese Expert Consensus on the diagnosis and treatment of advanced NSCLC (2016 version) (20) with TKI being the preferred $1 \mathrm{st}$ line option. However, platinum-based regimen remains the standard treatment for patients without mutations in China with gemcitabine, docetaxel, paclitaxel and pemetrexed being the most common choices for 1 st line chemotherapy (21). A retrospective chart review study examining realworld treatment pattern in Japan revealed EGFRTKIs to be the most commonly prescribed drug for EGFR mutated NSCLC across all treatment lines (22).

Pemetrexed is the preferred regimen in patients with NSCLC adenocarcinoma based on the results of previous randomized studies due to its superior outcomes in terms of PFS $(23,24)$. Likewise, even in current study, Pemetrexed $(30.3 \%, 22.7 \%)$ and Cisplatinum $(23.9 \%, 13.6 \%)$ were the most frequently used chemotherapeutic drugs as 1 st and 2nd line, respectively whereas, among TKIs, Gefitinib $(31.5 \%, 17.4 \%)$ and Icotinib $(20.3 \%, 15.9 \%)$ were the frequently used treatment in 1 st and 2 nd line, respectively. This treatment pattern is not in line with other patterns reported elsewhere wherein docetaxel was used in $14.0-16.0 \%$ of patients in 2 nd line $(25,26)$.

Our study revealed that although non-significant, EGFR+ patients who received sequential TKI and chemotherapy had longer median OS. This corroborates findings from a study by Chung et.al who demonstrated that the 1st line chemotherapy followed by EGFR-TKIs in EGFR+ advanced lung 
adenocarcinoma had better OS than that of 1 st line TKIs followed by 2nd-line chemotherapy (median: 662 versus 390 days, $P<0.0001$. Similar findings were reported by another phase III study, OPTIMAL which showed improved OS in patients receiving sequential combination of TKI and chemotherapy than those who received either TKI or chemotherapy (29.7 versus 20.7 or 11.2 months respectively, $\mathrm{P}<0.0001$ ) (27). Overall, these findings strongly support the fact that TKI in combination with chemotherapy is efficient when compared to either TKI or chemotherapy alone for treating EGFR+ mutation patients.

In our study, targeted therapy either using TKI alone or sequential chemotherapy was found to have better OS in EGFR + patients compared to EGFR-patients highlighting the importance of TKI in first line setting for EGFR + patients. This is in line with findings from a recent trial which reported the OS of Icotinib plus pemetrexed and carboplatin to be 36 months (28). Similarly, another study comparing the efficacy of combination therapy of EGFR-TKI with chemotherapy with EGFR-TKI alone and chemotherapy alone revealed significant improved PFS in combination therapy compared to EGFR-TKI alone (29). Additionally, combination therapy was better compared to chemotherapy alone both in PFS and OS in EGFR+ NSCLC patients. In our study the median OS in EGFR + patients receiving TKI alone was 27.9 months compared to 14.5 months in EGFR-patients who received chemotherapy. Results from our real-world study support the efficacy of EGFRTKIs as established in clinical trials.

Going forward, remarkable progress made in treatment of NSCLC is due to the discovery of several, clinically relevant activating pathways including EGFR-activating mutations and $A L K$ rearrangements (30) and treatment guidelines recommend the use of first line EGFR-TKI for patients with exon 19 deletions and the exon 21 L858R mutation (6). Data also reflect that patients harbouring exon 19 deletions or exon $21 \mathrm{~L} 858 \mathrm{R}$ point mutations in EGFR show substantially increased benefit from treatment with EGFRTKIs compared to those who do not harbour these mutations (31). This has been attributed to TKI's inhibitory action and its role in downstream signalling of EGFR. The mechanism of action of TKI is to inhibit the kinase activation and signal transduction downstream by binding to the ATP binding site of the kinase domain of EGFR (32). Treatment with TKI has shown around $74.0 \%$ response rate with a median PFS of 10.0-14.0 months $(12,15)$. However, recent studies have shown mixed outcomes due to exon 19 and 21 mutations in such patients in response to both EGFR-TKIs and chemotherapy (33-35). These difference in response between EGFR exon 19 deletions and exon 21 L858R mutation might be related to intrinsic structural basis and differential drug sensitivity (36-38). In our study, median OS was not reached in patients with exon 19 deletion and it was 21.4 months (95\% Cl: 16.7-35.6) in those with exon $21 \mathrm{~L} 858 \mathrm{R}$ mutation $(P=0.038)$. This was in agreement with study findings reported elsewhere. Jiang et.al reported significantly improved overall response rate (ORR) and PFS in patients with deletions in exon 19 compared with those with exon 21 mutation following EGFR-TKI treatment for NSCLC (31). The same was re-confirmed by Banno et.al wherein NSCLC patients with EGFR exon 19 deletions had a significant advantage following the treatment of Afatinib compared with the patients with EGFR exon 21 mutations (39). These findings re-substantiate the importance of appropriate treatment selection especially for EGFR+ NSCLC patients. With the approval of first immuno-oncology agent, Opdivo (Nivolumab injection) by China National Drug Administration based on results of pivotal phase III, Checkmate-078 trial that demonstrated significantly better OS with nivolumab compared to docetaxel in 
previously treated non-mutated EGFR/ALK NSCLC, better management is foreseen in this subset of patients (40). ALK-rearrangement has been identified in many cancers including NSCLC. ALKrearrangement leads to oncogenic $A L K$ tyrosine kinase that drives cell proliferation by activating downstream signalling pathways (41). ALK-TKIs are preferred option in advanced NSCLC with $A L K$ rearrangements $(42,43)$.

The strengths of the study are that this multicentric survey demonstrated the real-world treatment patterns and the survival benefits of EGFR TKIs, and other systemic therapies in EGFR mutated advanced NSCLC in first line, second- and third-line setting. Additionally, this study reports the 2-year follow-up data for treatment and survival parameters. Limitations of this analysis are reflective of the data source and collection. Few of the treatment information in our study was unavailable due to loss to follow up, thereby plausibly causing non-significant findings for the first line treatment parameters. It is also important to note that a longer and continuous follow up may yield completer data especially for OS.

\section{Conclusions}

OS for patients with advanced non-squamous NSCLC patients aligned with previous trials. EGFR-mutated patients who received both TKI and chemotherapy had a longer median OS, and patients with EGFR wildtype and $A L K$-negative NSCLC showed a longer median OS with pemetrexed-based first line chemotherapy compared to those with non-pemetrexed-based chemotherapy.

\section{Abbreviations}

OS

Overall survival

PFS

Progression free survival

NSCLC

Non-small cell lung cancer

EGFR

Epidermal growth factor receptor

ALK

Anaplastic lymphoma kinase

TKI

Tyrosine kinase inhibitor

PDL-1

Programmed death ligand 1

CTONG

Chinese Thoracic Oncology Group

MERAF

Medical Record Abstraction Form 
ECOG

Eastern Cooperative Oncology Group

PS

Performance Status

KM

Kalpan-Meier method

Cl

Confidence intervals

\section{Declarations}

\section{Ethics approval and consent to participate:}

The protocol was approved by the Research Ethics Committee of the Guangdong General Hospital, Guangzhou, Guangdong, China. Each site obtained its own institutional review board (IRB) or ethics committee approval before the start of the study. The study was conducted in accordance with the Declaration of Helsinki. Informed consent was waived by IRB for this retrospective analysis, except the IRB of Harbin Medical University Cancer Hospital.

\section{Consent for publication:}

Not Applicable

\section{Availability of data and material:}

The datasets used or analysed during the current study are available from the corresponding author on reasonable request.

\section{Competing interests:}

LLY, LJZ and XM are employees of Lilly Suzhou Pharmaceutical Co., China. XWL is an employee from Shanghai Centennial Scientific Co., Ltd. Y-LW has received speaker fees from AstraZeneca, Roche, Boehringer Ingelheim, Eli Lilly, Pfizer, BMS, and MSD. QZ has received speaker fees from AstraZeneca, Roche.

\section{Funding:}

This work was supported by National Key R\&D Program of China (Grant No. 2016 YFC 1303800) and High-level Hospital Construction Project (Grant No. DFJH201810).

\section{Authors Contributions:}


QZ, YS, XZ, GC and YZ proposed the conception and designed the study. PY, JC, ZY, YH and XS acquired the study data $\mathrm{DZ}, \mathrm{GF}, \mathrm{LY}, \mathrm{LZ}, \mathrm{XM}, \mathrm{XL}, \mathrm{YW}$ analyzed, and interpreted the study data. All the authors critically reviewed the manuscript and approved the final version for submission. All authors have agreed both to be personally accountable for the author's own contributions and to ensure that questions related to the accuracy or integrity of any part of the work, even ones in which the author was not personally involved, are appropriately investigated, resolved, and the resolution documented in the literature.

\section{Acknowledgments}

The authors would like to thank all study participants. This study was supported by the Chinese Thoracic Oncology Group (CTONG), a national collaborative clinical research group of 37 member hospitals.

The authors would also like to thank Junjun Liu from Eli Lilly and Company for preparing the first draft and the final revision, review and critical suggestions for improvement.

The authors would like to thank Dr Anuradha Nalli and Dr Priyanka Bannikoppa, Indegene Pvt. Ltd. for medical writing support in the preparation of this manuscript.

\section{References}

1. Bray F, Ferlay J, Soerjomataram I, Siegel RL, Torre LA, Jemal A. Global cancer statistics 2018 : GLOBOCAN estimates of incidence and mortality worldwide for 36 cancers in 185 countries. CA Cancer J Clin. 2018 Nov;68(6):394-424.

2. Globocan. The Global Cancer Observatory: China [Internet]. 2018. Available from: http://gco.iarc.fr/today/data/factsheets/populations/160-china-fact-sheets.pdf.

3. Zappa C, Mousa SA. Non-small cell lung cancer: current treatment and future advances. Transl Lung Cancer Res. 2016 Jun;5(3):288-300.

4. Cao M, Chen W. Epidemiology of lung cancer in China. Thorac Cancer. 2019;10(1):3-7.

5. Chen W, Zheng R, Baade PD, Zhang S, Zeng H, Bray F, et al. Cancer statistics in China, 2015. CA Cancer J Clin. 2016 Apr;66(2):115-32.

6. National Comprehensive Cancer Network. Clinical practice guidelines in oncology (NCCN Guidelines): non-small cell lung cancer. Fort Washington: National Comprehensive Cancer Network, Inc.; 2018. Report No.: version 1. 2018.

7. Dearden S, Stevens J, Wu Y-L, Blowers D. Mutation incidence and coincidence in non small-cell lung cancer: meta-analyses by ethnicity and histology (mutMap). Ann Oncol Off J Eur Soc Med Oncol. 2013 Sep;24(9):2371-6.

8. Batson S, Mitchell SA, Windisch R, Damonte E, Munk VC, Reguart N. Tyrosine kinase inhibitor combination therapy in first-line treatment of non-small-cell lung cancer: systematic review and network meta-analysis. OncoTargets Ther. 2017;10:2473-82. 
9. Juan O, Popat S. Treatment choice in epidermal growth factor receptor mutation-positive non-small cell lung carcinoma: latest evidence and clinical implications. Ther Adv Med Oncol. 2017 Mar;9(3):201-16.

10. Wu Y-L, Zhou C, Liam C-K, Wu G, Liu X, Zhong Z, et al. First-line erlotinib versus gemcitabine/cisplatin in patients with advanced EGFR mutation-positive non-small-cell lung cancer: analyses from the phase III, randomized, open-label, ENSURE study. Ann Oncol Off J Eur Soc Med Oncol. 2015 Sep;26(9):1883-9.

11. Zhou C, Wu Y-L, Chen G, Feng J, Liu X-Q, Wang C, et al. Erlotinib versus chemotherapy as first-line treatment for patients with advanced EGFR mutation-positive non-small-cell lung cancer (OPTIMAL, CTONG-0802): a multicentre, open-label, randomised, phase 3 study. Lancet Oncol. 2011 Aug;12(8):735-42.

12. Rosell R, Carcereny E, Gervais R, Vergnenegre A, Massuti B, Felip E, et al. Spanish Lung Cancer Group in collaboration with Groupe Français de Pneumo-Cancérologie and Associazione Italiana Oncologia Toracica. Erlotinib versus standard chemotherapy as first-line treatment for European patients with advanced EGFR mutation-positive non-small-cell lung cancer (EURTAC): a multicentre, open-label, randomised phase 3 trial. Lancet Oncol. 2012 Mar;13(3):239-46.

13. Mok TS, Wu Y-L, Thongprasert S, Yang C-H, Chu D-T, Saijo N, et al. Gefitinib or carboplatin-paclitaxel in pulmonary adenocarcinoma. N Engl J Med. 2009 Sep;3(10):947-57. 361(.

14. Han J-Y, Park K, Kim S-W, Lee DH, Kim HY, Kim HT, et al. First-SIGNAL: first-line single-agent iressa versus gemcitabine and cisplatin trial in never-smokers with adenocarcinoma of the lung. J Clin Oncol Off J Am Soc Clin Oncol. 2012 Apr 1;30(10):1122-8.

15. Maemondo M, Inoue A, Kobayashi K, Sugawara S, Oizumi S, Isobe H, et al. North-East Japan Study Group. Gefitinib or chemotherapy for non-small-cell lung cancer with mutated EGFR. N Engl J Med. 2010 Jun;24(25):2380-8. 362(.

16. Sequist LV, Yang JC-H, Yamamoto N, O’Byrne K, Hirsh V, Mok T, et al. Phase III study of afatinib or cisplatin plus pemetrexed in patients with metastatic lung adenocarcinoma with EGFR mutations. J Clin Oncol Off J Am Soc Clin Oncol. 2013 Sep;20(27):3327-34. 31(.

17. Li H, Wang C, Wang Z, Hu Y, Zhang G, Zhang M, et al. Efficacy and long-term survival of advanced lung adenocarcinoma patients with uncommon EGFR mutations treated with 1st generation EGFRTKIs compared with chemotherapy as first-line therapy. Lung Cancer Amst Neth. 2019 Apr;130:42-9.

18. Schneeweiss S, Eichler H-G, Garcia-Altes A, Chinn C, Eggimann A-V, Garner S, et al. Real World Data in Adaptive Biomedical Innovation: A Framework for Generating Evidence Fit for Decision-Making. Clin Pharmacol Ther. 2016;100(6):633-46.

19. Jadhav S. Using real world data to enhance clinical trials. [Internet]. Available from: http://www. clinicalinformaticsnews.com/2017/1/13/using-real-world-data-to-enhance-clinical-trials.aspx.

20. Shi Y, Sun Y, Yu J, Ding C, Wang Z, Wang C, et al. China experts consensus on the diagnosis and treatment of advanced stage primary lung cancer (2016 version). Asia Pac J Clin Oncol. 2017;13(1):87-103. 
21. Xue $C$, Hu Z, Jiang W, Zhao Y, Xu F, Huang Y, et al. National survey of the medical treatment status for non-small cell lung cancer (NSCLC) in China. Lung Cancer Amst Neth. 2012 Aug;77(2):371-5.

22. Isobe $H$, Mori K, Minato K, Katsura H, Taniguchi K, Arunachalam A, et al. Real-world practice patterns for patients with advanced non-small cell lung cancer: multicenter retrospective cohort study in Japan. Lung Cancer Auckl NZ. 2017;8:191-206.

23. Jo J, Kim SH, Kim YJ, Lee J, Kim M, Keam B, et al. Efficacy of Pemetrexed-based Chemotherapy in Comparison to Non-Pemetrexed-based Chemotherapy in Advanced, ALK + Non-Small Cell Lung Cancer. Yonsei Med J. 2018 Mar;59(2):202-10.

24. Paz-Ares L, de Marinis F, Dediu M, Thomas M, Pujol J-L, Bidoli P, et al. Maintenance therapy with pemetrexed plus best supportive care versus placebo plus best supportive care after induction therapy with pemetrexed plus cisplatin for advanced non-squamous non-small-cell lung cancer (PARAMOUNT): a double-blind, phase 3, randomised controlled trial. Lancet Oncol. 2012 Mar;13(3):247-55.

25. McKay C, Burke T, Cao X, Abernethy AP, Carbone DP. Treatment Patterns for Advanced Non-Small-cell Lung Cancer After Platinum-containing Therapy in U.S. Community Oncology Clinical Practice. Clin Lung Cancer. 2016;17(5):449-60.e7.

26. Nadler E, Espirito JL, Pavilack M, Boyd M, Vergara-Silva A, Fernandes A. Treatment Patterns and Clinical Outcomes Among Metastatic Non-Small-Cell Lung Cancer Patients Treated in the Community Practice Setting. Clin Lung Cancer. 2018 Jul;19(4):360-70.

27. Zhou C, Wu YL, Chen G, Feng J, Liu X-Q, Wang C, et al. Final overall survival results from a randomised, phase III study of erlotinib versus chemotherapy as first-line treatment of EGFR mutation-positive advanced non-small-cell lung cancer (OPTIMAL, CTONG-0802). Ann Oncol. 2015 Sep;26(9):1877-83.

28. Xu L, Qi Q, Zhang Y, Cui J, Liu R, Li Y. Combination of icotinib and chemotherapy as first-line treatment for advanced lung adenocarcinoma in patients with sensitive EGFR mutations: A randomized controlled study. Lung Cancer Amst Neth. 2019 Jul;133:23-31.

29. Wen M, Xia J, Sun Y, Wang X, Fu X, Zhang Y, et al. Combination of EGFR-TKIs with chemotherapy versus chemotherapy or EGFR-TKIs alone in advanced NSCLC patients with EGFR mutation. Biol Targets Ther. 2018;12:183-90.

30. Lindeman NI, Cagle PT, Beasley MB, Chitale DA, Dacic S, Giaccone G, et al. Molecular Testing Guideline for Selection of Lung Cancer Patients for EGFR and ALK Tyrosine Kinase Inhibitors. J Mol Diagn. 2013 Jul;15(4):415-53.

31. $10.3892 / \mathrm{mco} .2019 .1881$

Jiang H, Zhu M, Li Y, Li Q. Association between EGFR exon 19 or exon 21 mutations and survival rates after first-line EGFR-TKI treatment in patients with non-small cell lung cancer. Mol Clin Oncol [Internet]. 2019 Jun 18 [cited 2019 Aug 27]; Available from: http://www.spandidospublications.com/10.3892/mco.2019.1881. 
32. Du Z, Lovly CM. Mechanisms of receptor tyrosine kinase activation in cancer. Mol Cancer. 2018;19(1):58. 17(.

33. Zhang Y, Sheng J, Kang S, Fang W, Yan Y, Hu Z, et al. Patients with exon 19 deletion were associated with longer progression-free survival compared to those with L858R mutation after first-line EGFRTKIs for advanced non-small cell lung cancer: a meta-analysis. PloS One. 2014;9(9):e107161.

34. Yang JC-H, Wu Y-L, Schuler M, Sebastian M, Popat S, Yamamoto N, et al. Afatinib versus cisplatinbased chemotherapy for EGFR mutation-positive lung adenocarcinoma (LUX-Lung 3 and LUX-Lung 6): analysis of overall survival data from two randomised, phase 3 trials. Lancet Oncol. 2015 Feb;16(2):141-51.

35. Lee CK, Wu Y-L, Ding PN, Lord SJ, Inoue A, Zhou C, et al. Impact of Specific Epidermal Growth Factor Receptor (EGFR) Mutations and Clinical Characteristics on Outcomes After Treatment With EGFR Tyrosine Kinase Inhibitors Versus Chemotherapy in EGFR-Mutant Lung Cancer: A Meta-Analysis. J Clin Oncol Off J Am Soc Clin Oncol. 2015 Jun;10(17):1958-65. 33(.

36. Eck MJ, Yun C-H. Structural and mechanistic underpinnings of the differential drug sensitivity of EGFR mutations in non-small cell lung cancer. Biochim Biophys Acta. 2010 Mar;1804(3):559-66.

37. Furuyama K, Harada T, Iwama E, Shiraishi Y, Okamura K, Ijichi K, et al. Sensitivity and kinase activity of epidermal growth factor receptor (EGFR) exon 19 and others to EGFR-tyrosine kinase inhibitors. Cancer Sci. 2013 May;104(5):584-9.

38. Zhu J, Zhong W, Zhang G, Li R, Zhang X, Guo A, et al. Better survival with EGFR exon 19 than exon 21 mutations in gefitinib-treated non-small cell lung cancer patients is due to differential inhibition of downstream signals. Cancer Lett. 2008 Jul 8;265(2):307-17.

39. Banno E, Togashi Y, Kobayashi Y, Hayashi H, Mitsudomi T, Nishio K. Afatinib is especially effective against non-small cell lung cancer carrying an EGFR exon 19 deletion. Anticancer Res. 2015 Apr;35(4):2005-8.

40. Wu Y-L, Lu S, Cheng Y, Zhou C, Wang J, Mok T, et al. Nivolumab Versus Docetaxel in a Predominantly Chinese Patient Population With Previously Treated Advanced NSCLC: CheckMate 078 Randomized Phase III Clinical Trial. J Thorac Oncol. 2019 May;14(5):867-75.

41. Huang H. Anaplastic Lymphoma Kinase (ALK) Receptor Tyrosine Kinase: A Catalytic Receptor with Many Faces. Int J Mol Sci. 2018 Nov 2;19(11).

42. Mezquita L, Besse B. Sequencing ALK inhibitors: alectinib in crizotinib-resistant patients, a phase 2 trial by Shaw et al. J Thorac Dis. 2016 Nov;8(11):2997-3002.

43. Solomon BJ, Mok T, Kim D-W, Wu Y-L, Nakagawa K, Mekhail T, et al. First-Line Crizotinib versus Chemotherapy in ALK-Positive Lung Cancer. N Engl J Med. 2014 Dec;4(23):2167-77. 371 (.

\section{Figures}


A
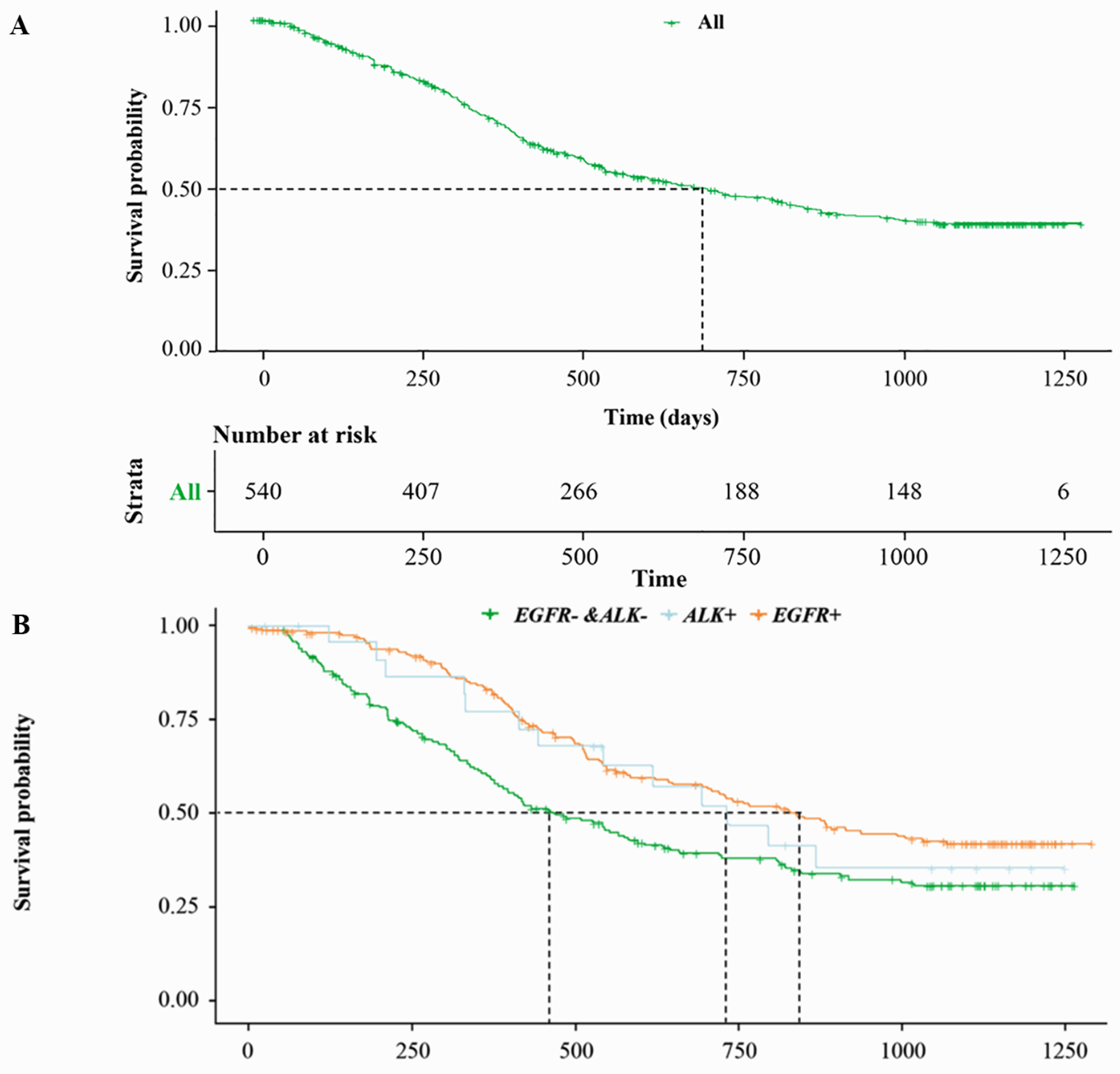

Number at risk

\begin{tabular}{|c|c|c|c|c|c|c|}
\hline 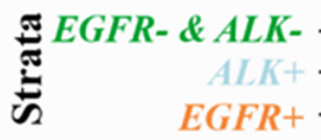 & $\begin{array}{r}183 \\
24 \\
203\end{array}$ & $\begin{array}{r}127 \\
19 \\
168\end{array}$ & $\begin{array}{r}78 \\
15 \\
118\end{array}$ & $\begin{array}{r}52 \\
9 \\
85\end{array}$ & $\begin{array}{r}38 \\
6 \\
66\end{array}$ & $\begin{array}{l}2 \\
0 \\
3\end{array}$ \\
\hline & 0 & 250 & 500 & 750 & 1000 & 1250 \\
\hline
\end{tabular}

\section{Figure 1}

KM curve for OS in patients with different mutations. (A) Median OS for all 540 patients was 21.4 months (95\% Cl: 18.1-25.5). (B) Median OS for patients with EGFR+, ALK+, EGFR-/ALK- were 27.9 months (95\% Cl: 23.4-NA), 24.5 months (95\% Cl: 18.1-NA) and 15.7 months (95\% Cl: 13.1-21.1), respectively. 


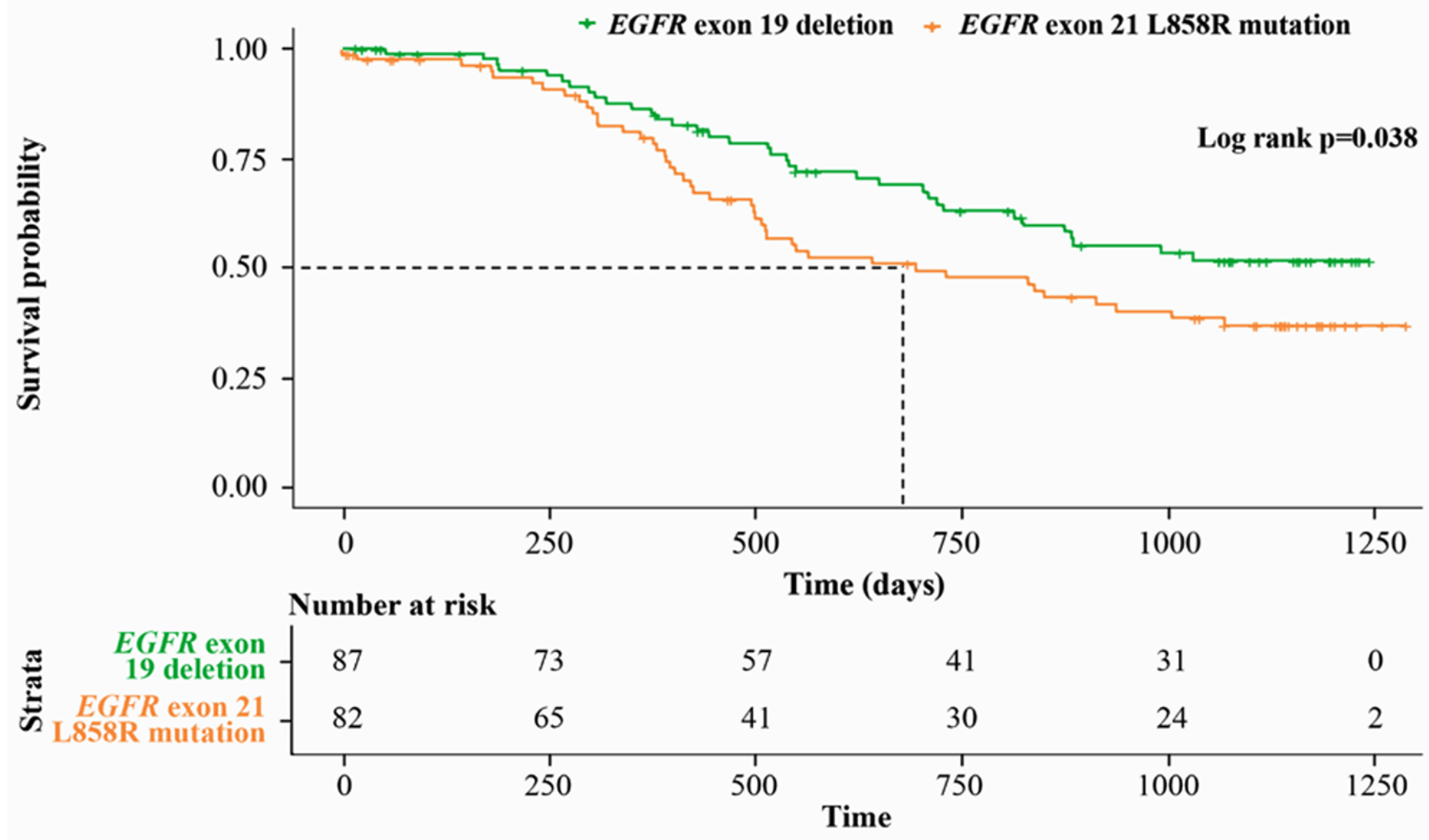

Figure 2

OS in patients with EGFR exon 19 deletion/exon 21 L858R mutation Median OS for EGFR exon 19 deletion had not reached and in patients with EGFR exon 21 L858R mutation it was 21.4 months (95\% Cl: 16.7-35.6). 
A
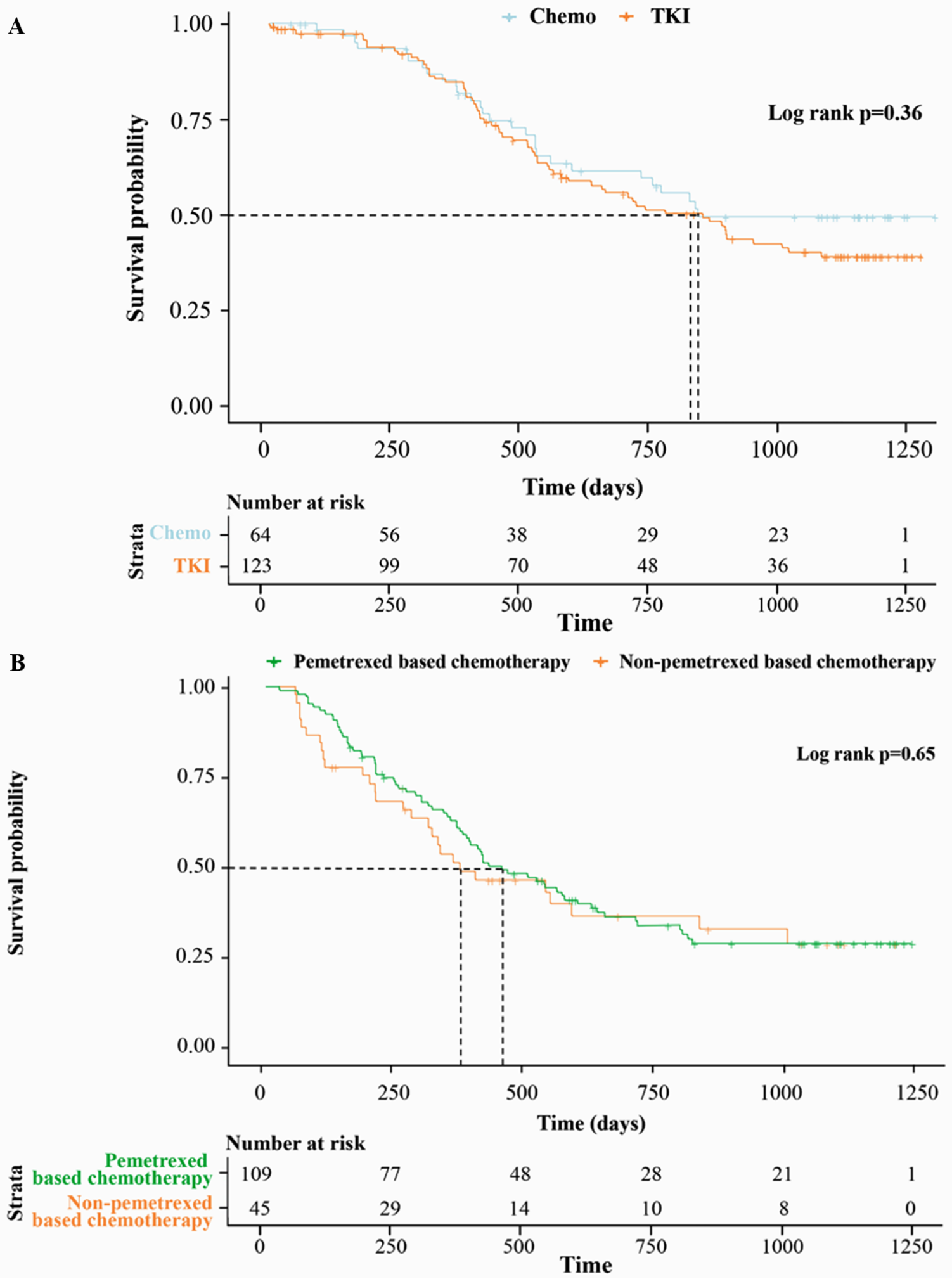

\section{Figure 3}

OS in patients received various 1st line treatments (A) Median OS was 27.7 months (95\%Cl: 19.5-NA) in EGFR+ patients who received chemotherapy and 27.9 months (95\% Cl: 19.3-35.6) in those who received TKI as 1 st line. (B) Median OS of patients treated with pemetrexed-based and non-pemetrexed-based chemotherapy were 15.6 months $(95 \% \mathrm{Cl}$ : 13.1-21.1) and 12.6 (95\% Cl: 10.6-33.9) months, respectively. 


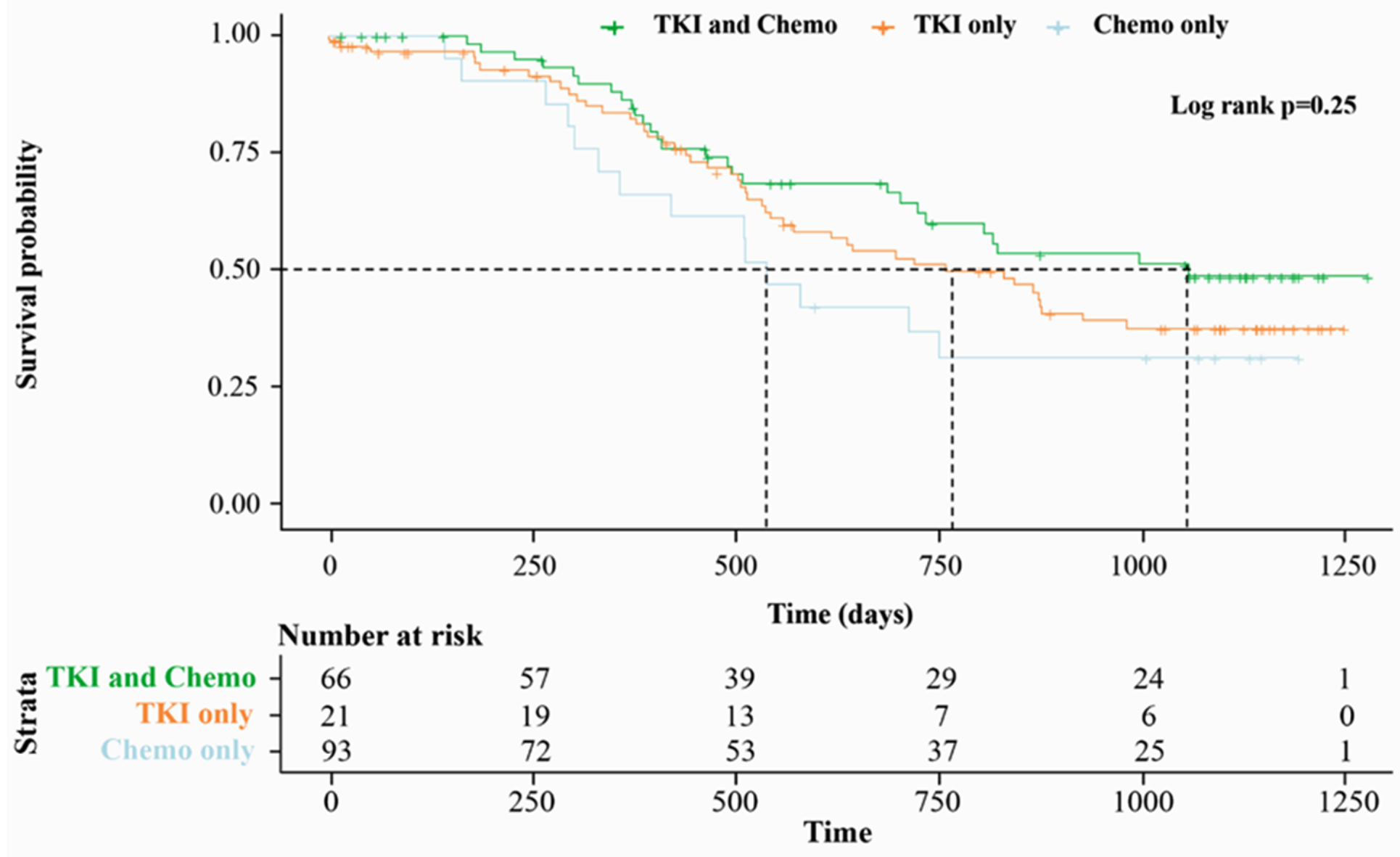

\section{Figure 4}

OS in EGFR+ patients who received all treatment course Median OS for patients who received TKI and chemotherapy: 35.6 months (95\% Cl: $24.4-\mathrm{NA})$; TKI only: 25.5 months (95\% Cl: 19.3-NA) and chemotherapy only: 18.1 months (95\% Cl: $12.1-\mathrm{NA})$. 